\title{
العناية بالناحية الجمالية والموسيقى اللفظية في سورة الواقعة

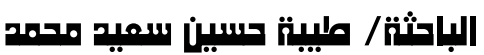

المقدمة:

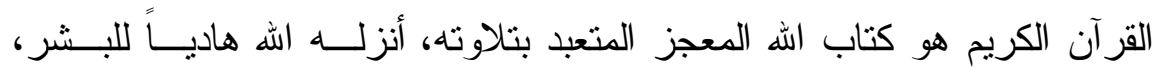

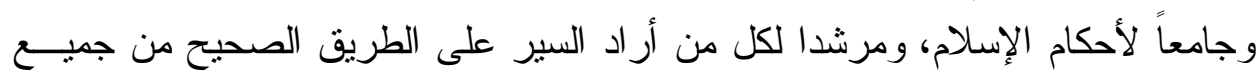

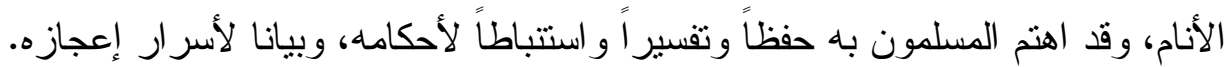

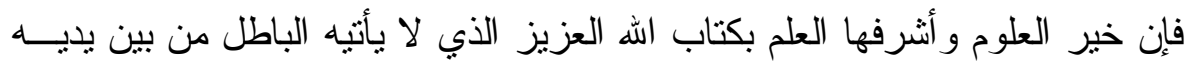

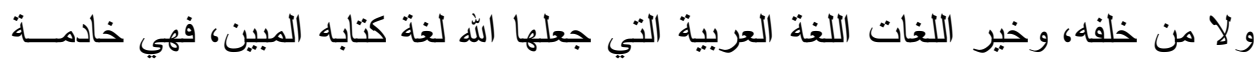

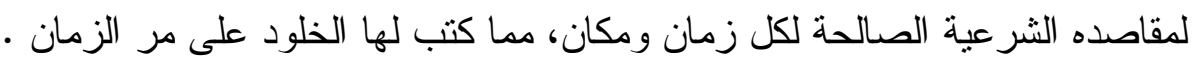

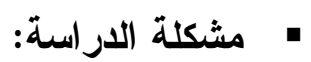

إن أول ما يشد ويجذب الناس إلى سماع سورة الواقعة هو جرس ألفاظها المتميـز

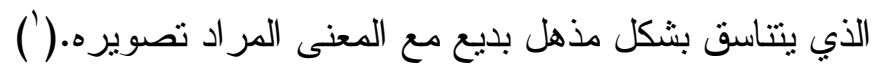

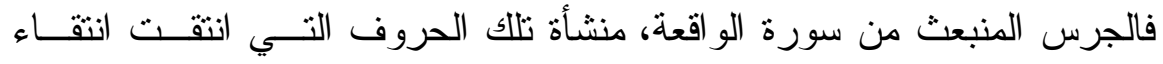

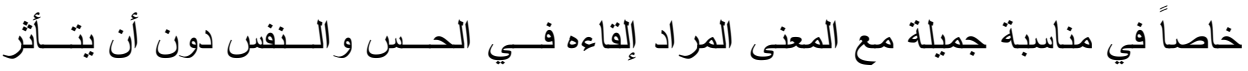

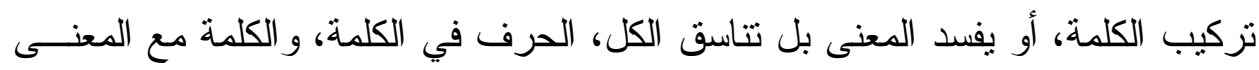

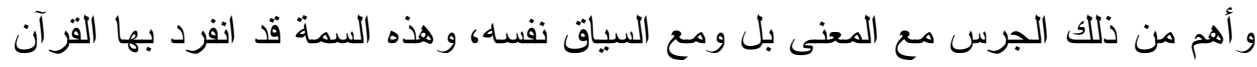

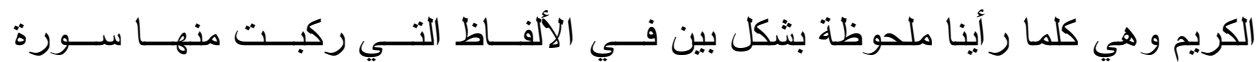

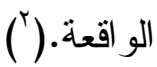

وقد اهتم بعض العلماء منذ وقت مبكر بدر اسة أسر ار الآيات ونظمها تحت مسمى

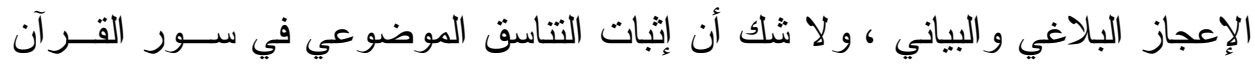

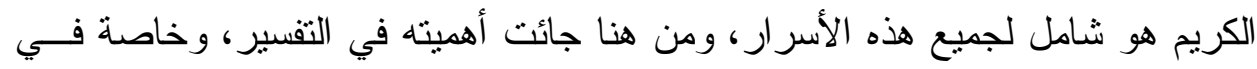

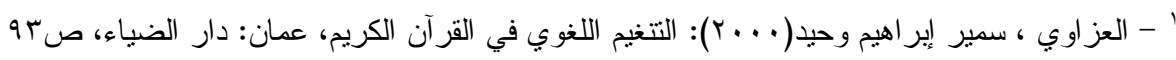

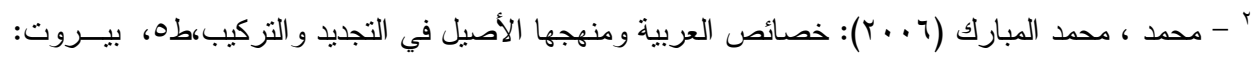

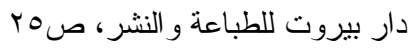


التفسير الموضوع مما يجعله يستحق البحث و الدر اسة، وهذه الدر اسة الوجيزة محاولـــة

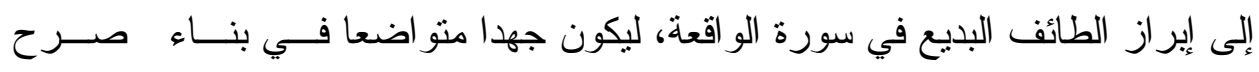

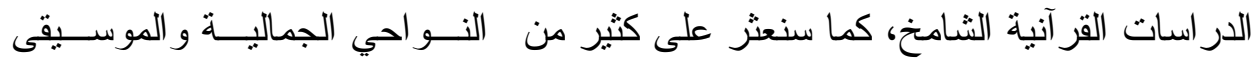
اللفظية في السورة الكريمة. أهداف الار اسة:

تهدف هذه الدراسة إلى تحقيق الأهداف التالية:

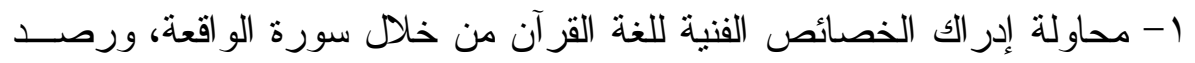
الظو اهر اللغوية والأسلوبية والتعرف على النوائهي الفي الجمالية فيها.

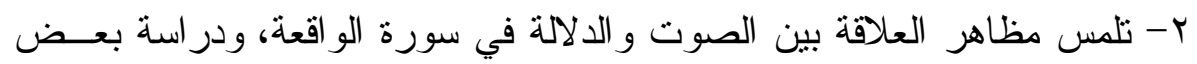

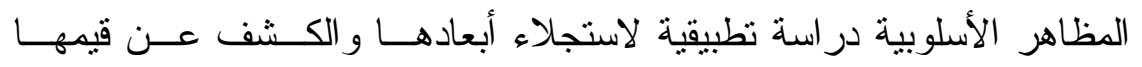
البلاغية و التعبيرية وتحديد مظاهر الموسيقى اللفظية في السورة. أهمية الار اسة: تتضح أهمية هذه الدر اسة من خلال اعتبار ات كثيرة منها يلي:

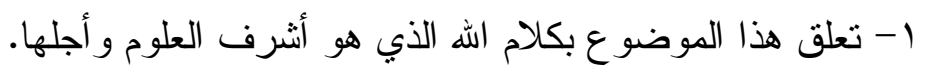
r- لفت الانتباه إلى جمال الألفاظ و المعاني في سورة الو لو القعة.

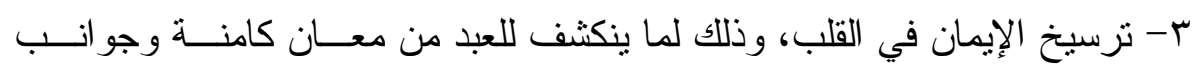

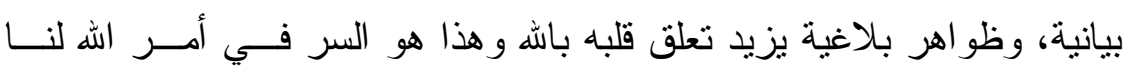

$$
\text { بتدبره. }
$$

ع - يثبت أن القرآن من عند الهه وذلك لأنه يظهر قضية الإعجاز البياني في أبهـى

$$
\text { صورة. }
$$

ه- أنه يتعلق بالوجه الذي تحدى الله به الخلق وهو الإعجاز البياني.

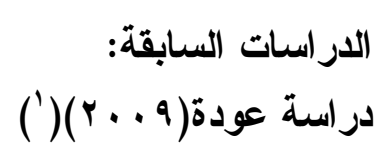
وقد تتاول هذا البحث النظم في القرآن الكريم ، ثم تحدث عــن الأســلوب و الأســلوبية

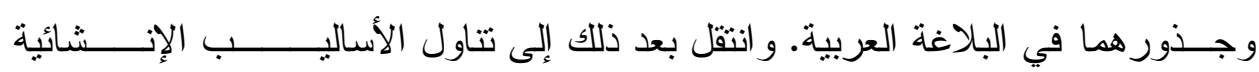

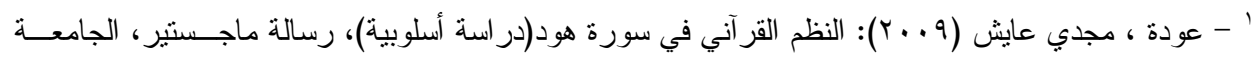
الإسلامية بغزة: كلية الآداب. 


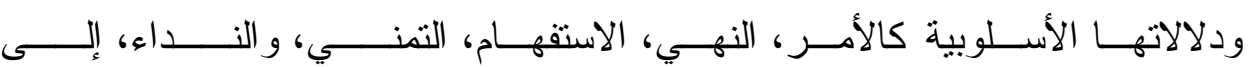

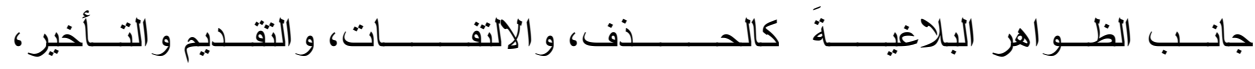

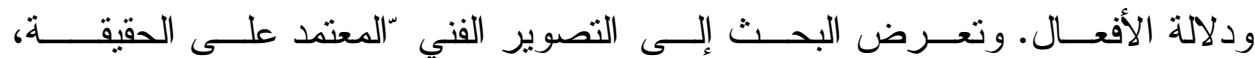

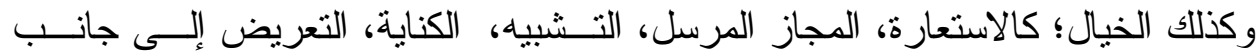

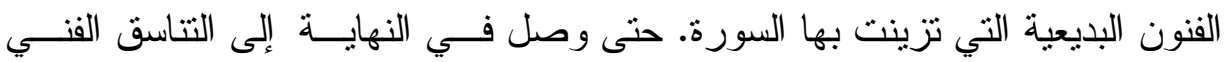

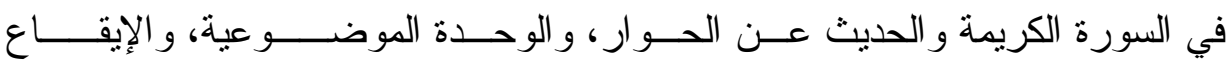

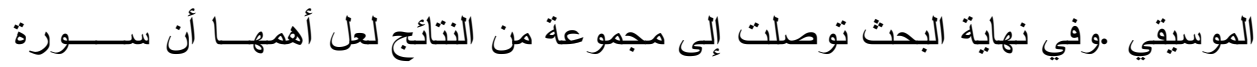
هــود تعـــد بحــق موسوعة لغوية للأساليب، ومعجماً المصطلحات البلاغية.

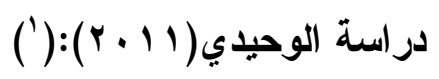

توصلت الدر اسة إلى أن الآية قد تأتي فاصلة لكل المقطع القر آني، ويحدث هذا خاصــة

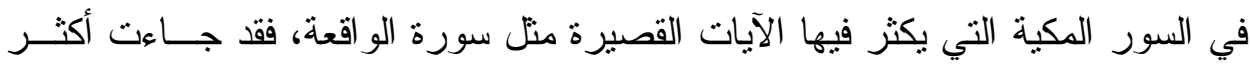
فو اصلها آيات تختم بها المقاطع القر آنية، كما اثنتلت الفو اصل على كثير من فئر الأساليب البلاغية مثل التقديم و التأخير ، و التوكيد، و الاستفهام، و الإضمار في موضع الإظهار .

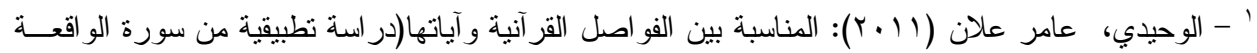

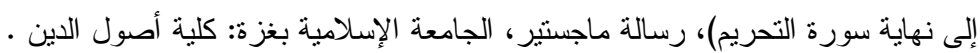




\section{نزول سورة الواقعة وفضلها :}

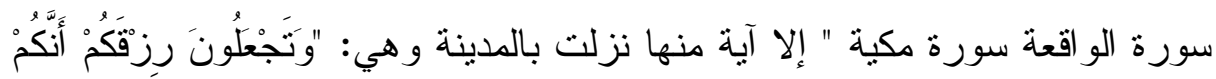

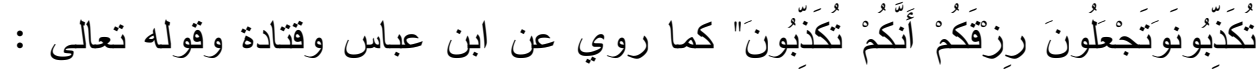

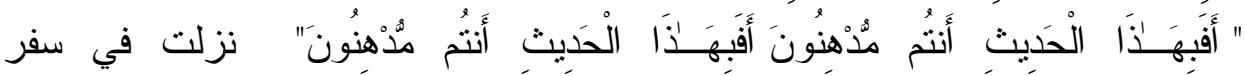

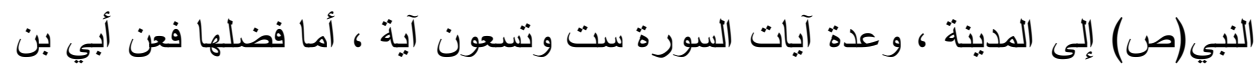

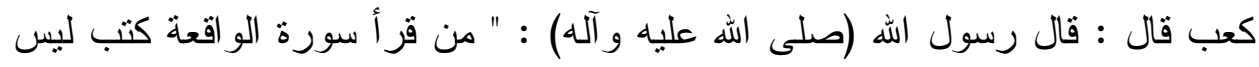

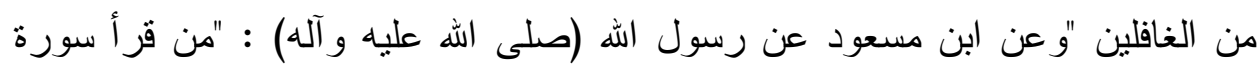
الو اقعة كل ليلة لم تصبه فاقة أبدا " وعن أنس عن رسول اله (صلى اله عليه و آله) :

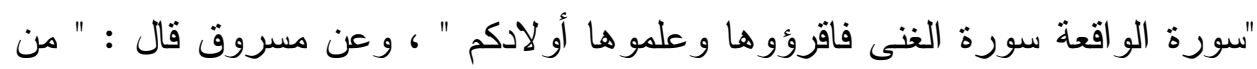

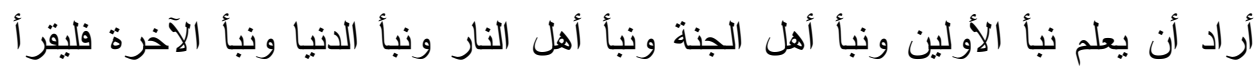

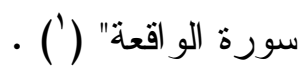
مظاهر المناسبة في سورة الو اقعة: للمناسبة في سورة الواقعة مظهران: ا ـ خارجي، ويتمثل في: مناسبة سورة الو اقعة لعدة سور من القرآن الكريم، ومناسبتها لما قبلها (سورة الرحمن) وما بعدها (سورة الحديد). r. داخلي، ويتمنل في: مناسبة عنوان السورة لمضمونها، ومناسبة مقدمة السورة السوة

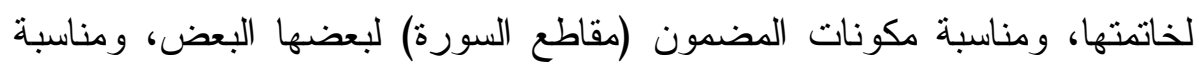

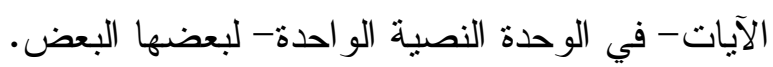
أولا: المظهر الخارجي: مناسبة سورة الواقعة لسور القرآن: آمطئ تظهر المناسبة بين سورة الواقعة وسور القرآن من خلاف لون ما يلي:

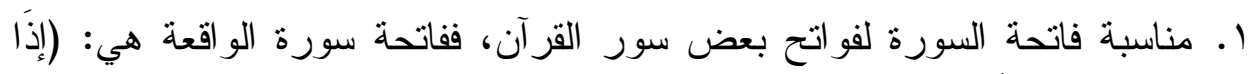

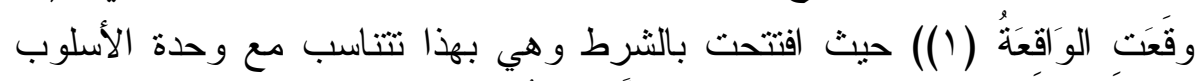

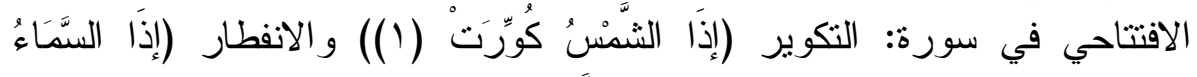

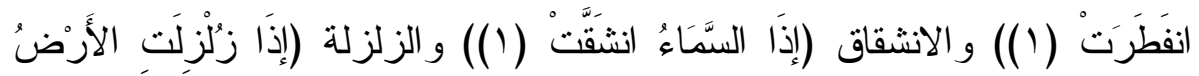

' - فياض، حسن حميد( (1) بـ): "الصورة المفردة و المركبة فى سورة الواقعة "، مجلة مركز دراسات الكوفة ،

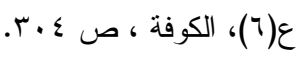


زلِْزَالَهَا (1)، كما أنها تتثق مع السور المذكورة في وحدة الموضوع، فجميع هذه

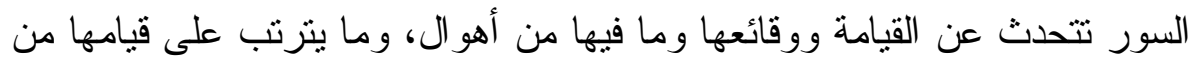
مكافأة المحسن ومعاقبة المسيء. r. مناسبة المضامين: فمضمون سورة الواقعة متناسب مع سائر سور القيامة كالحاقة

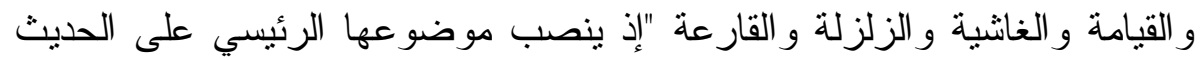

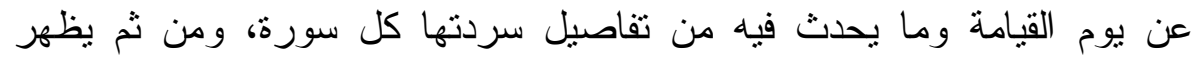

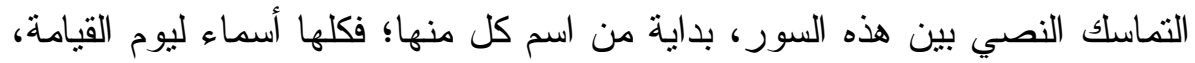

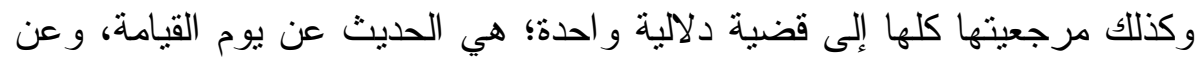

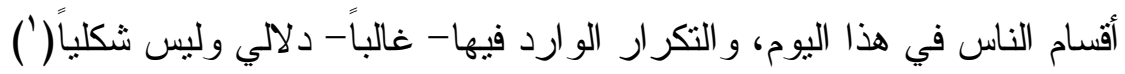
ومن النواحي الجمالية في السورة ما يلي: لئي

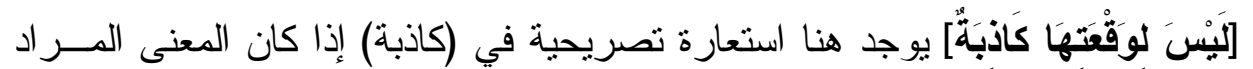

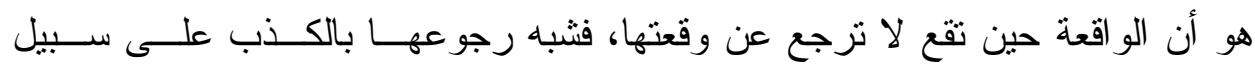

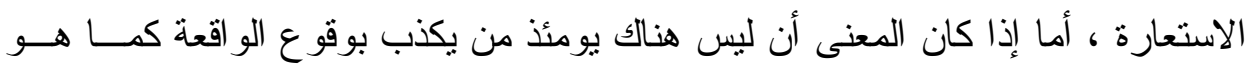

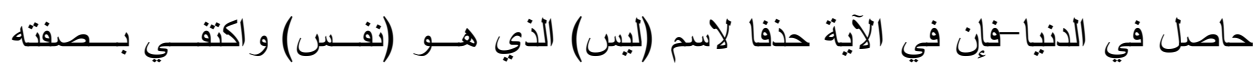

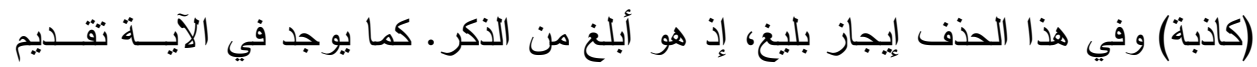

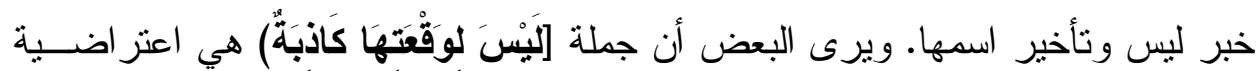

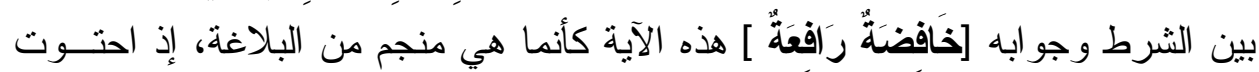

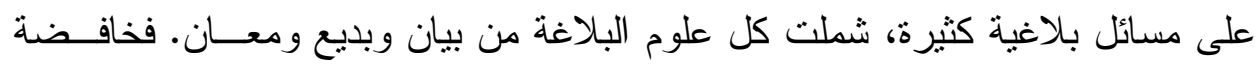

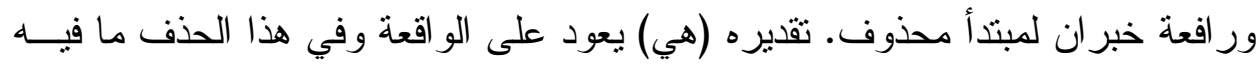

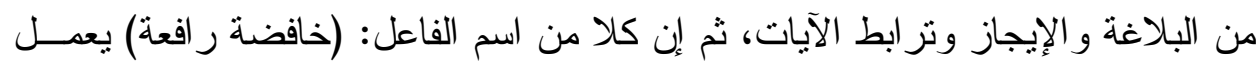

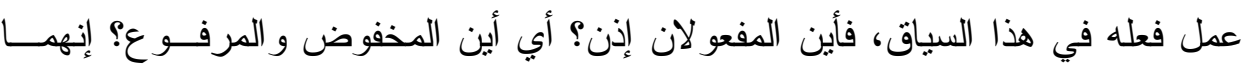

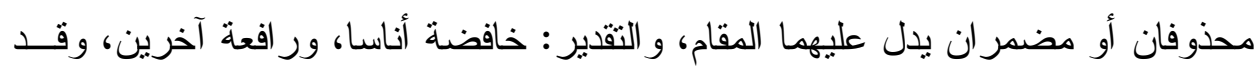

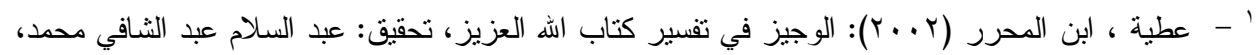
بيروت: دار الكتب العلمية. 
تعددت طرق الحذف في هذه الآية إذ حذف المبتدأ من أولها، ومفعول (خافــة) مسن

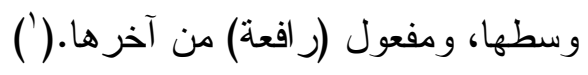

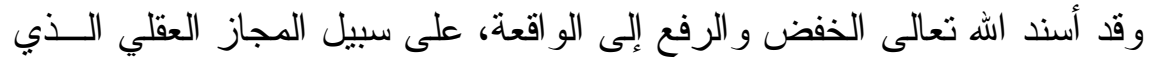

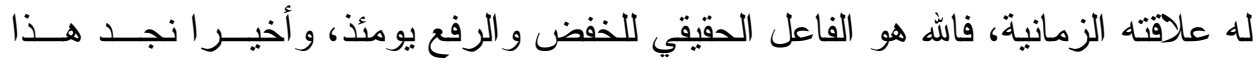

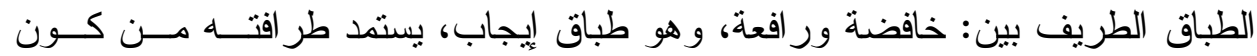

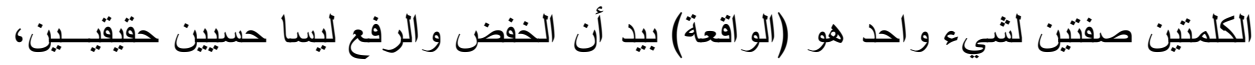

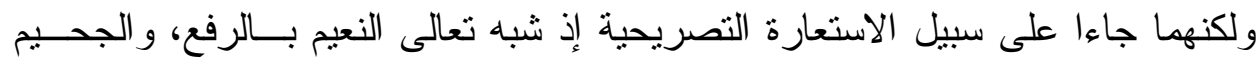

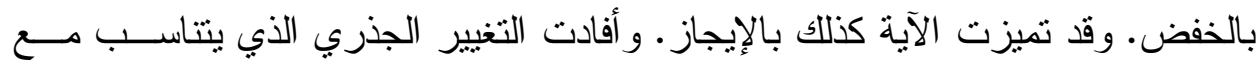

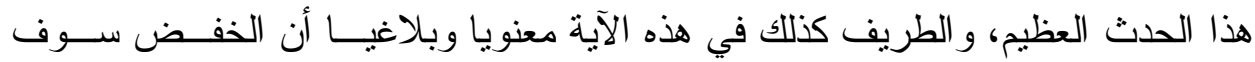

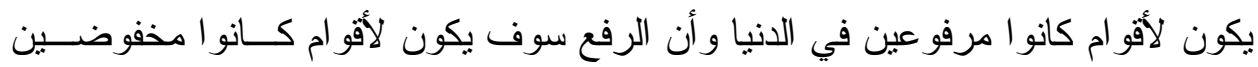

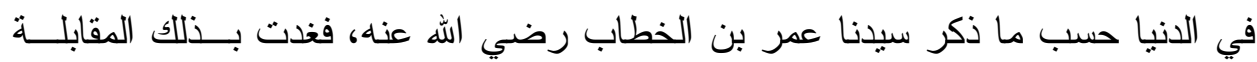
عميقة وشاملة إلى أن صارت بين حال الناس في الدنيا وحالهم في الآخرة على اختلاف

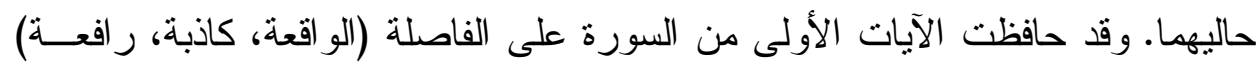
على ما في ذلك من إيقاع موح بالد الالة.

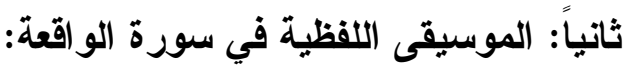

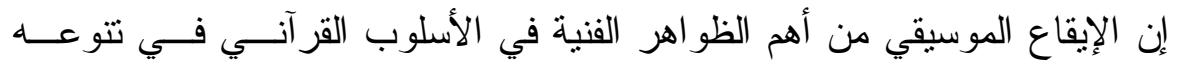

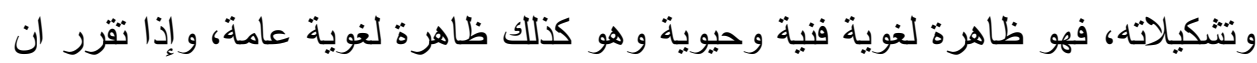

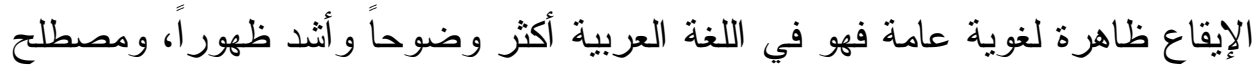
الإيقاع معروف عند العرب باختصاصه بالألحان و الغناء.

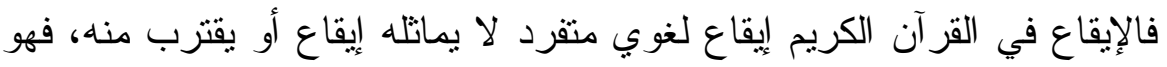

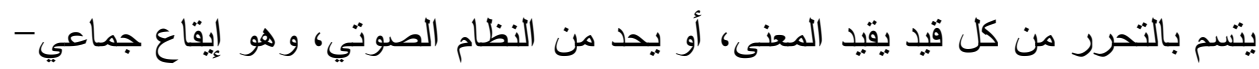
إن صح التعبير - منبعث من النص في تكوينه الصوتي و اللفظي تبرزه كل مكونات النص القر آني، فحروفه منتآخية في كلمات ذات إيقاع موسيقى ونغم تهتز المشاعر منه فئه

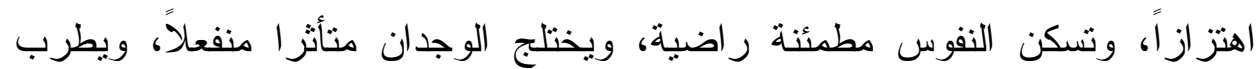

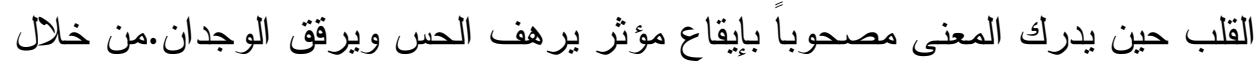

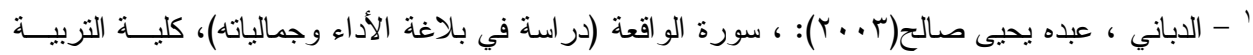


معرفتنا بالجوانب المهمة من الإعجاز الصوتي والنغمى في القرآن الكريم، يزداد

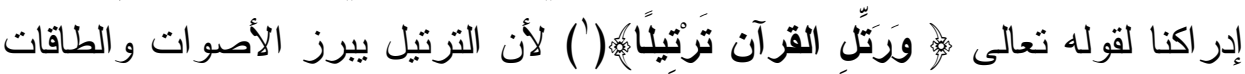

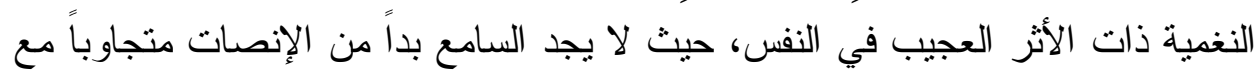

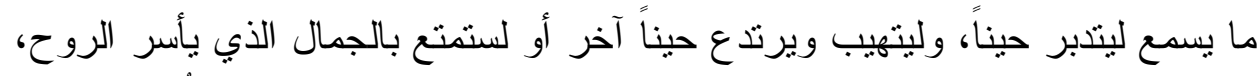

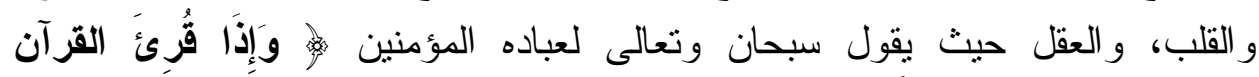

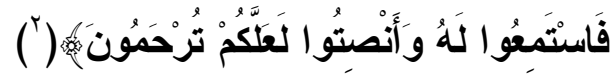

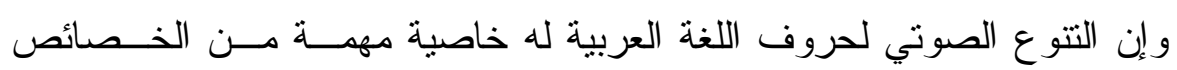

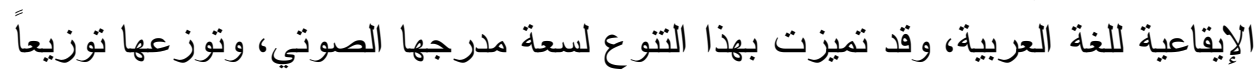

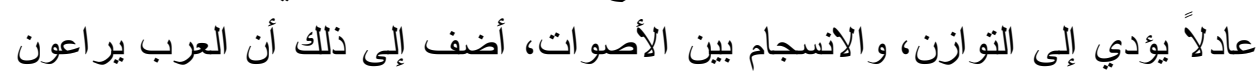

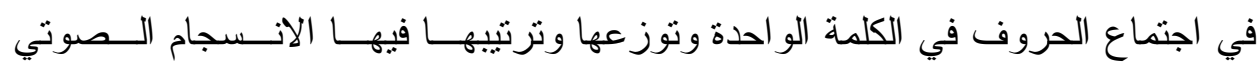
و التآلف الموسيقي، ولذلك تجنبو اجتماع الزابي مع الظاء و السين و الضاد و الذال و الجيم

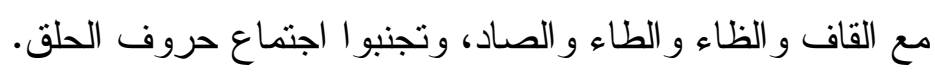

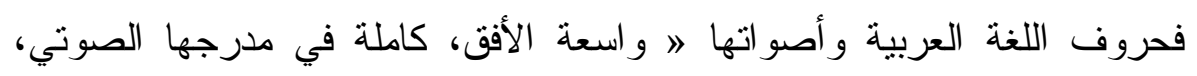
حسنة التوزيع للحروف و الأصوات في هذا المدرج، منميزة المخارج و الصفات ثابتة

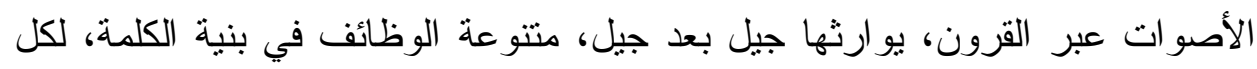

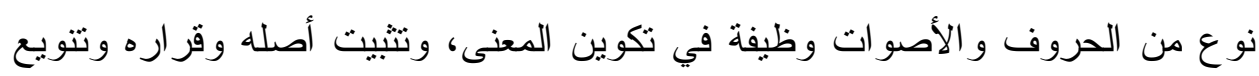

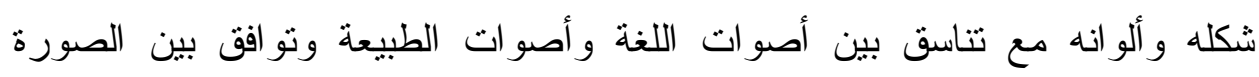

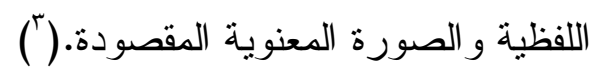

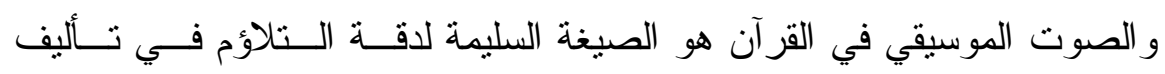

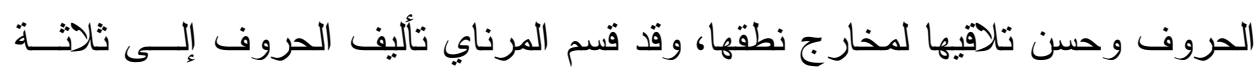

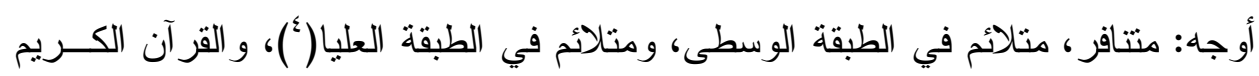

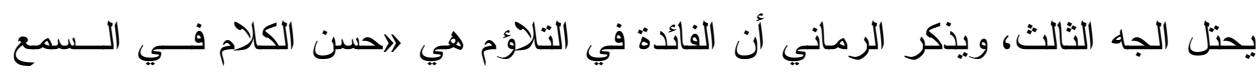

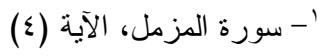

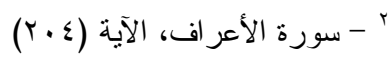

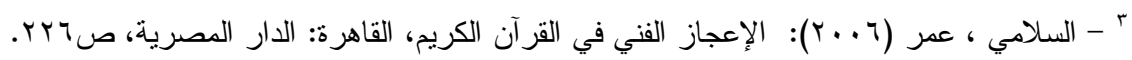

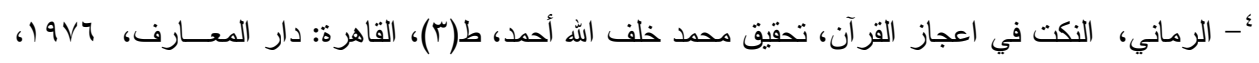
صV 
وسهولته في اللفظ وتقبل المعنى له في النفس لما ير اد عليها من حسن الصورة وطريقة

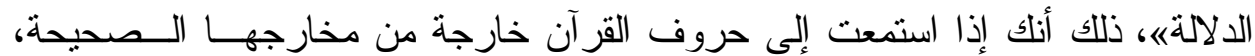

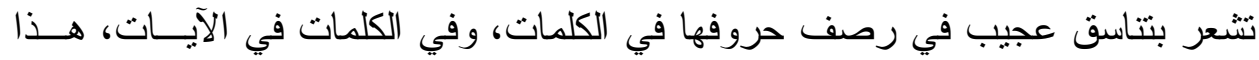

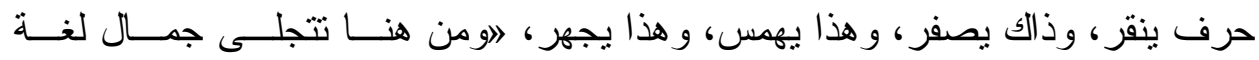

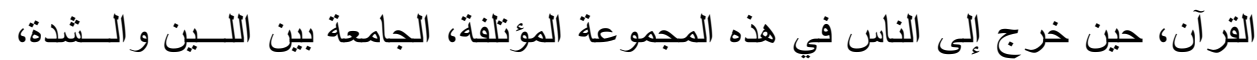

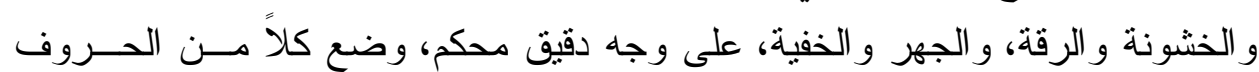

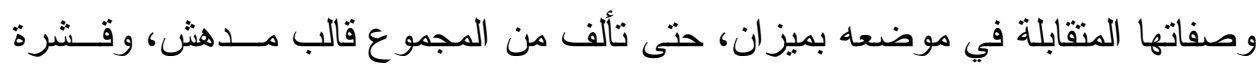

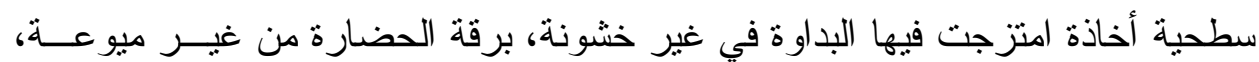

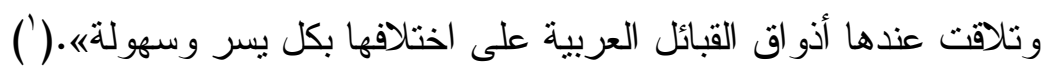

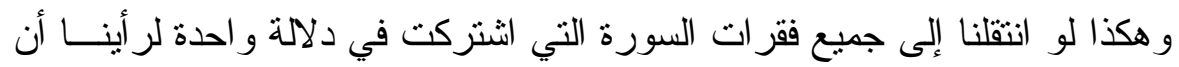

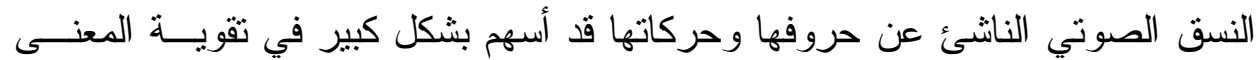
وتوضيحه مما كان له عظيم الأثر في المتلقين بما يحدثه الصوت فئ في نفوسهم.

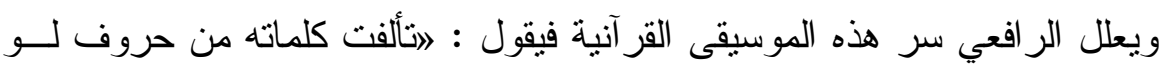

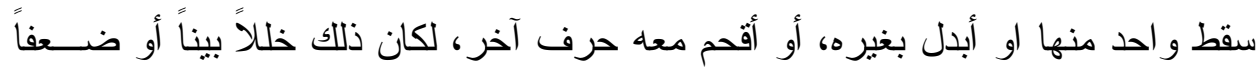
ظاهر اً في نسق الوزن وجرس النغمة، وفي حس السمع وذوق اللسان، وفــي انسـسجام

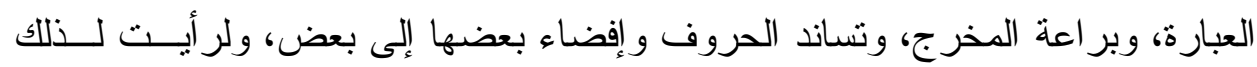

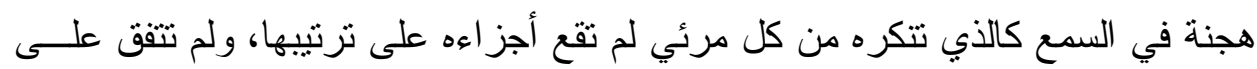

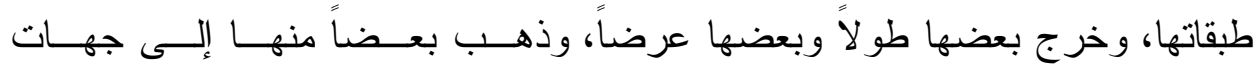

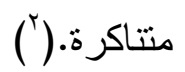

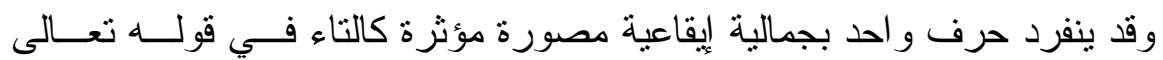

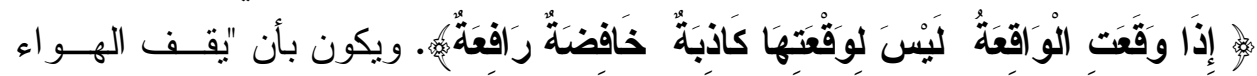

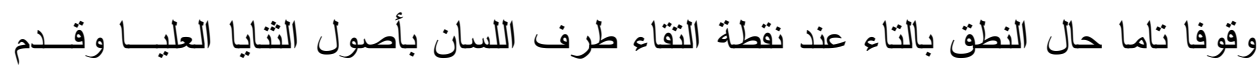

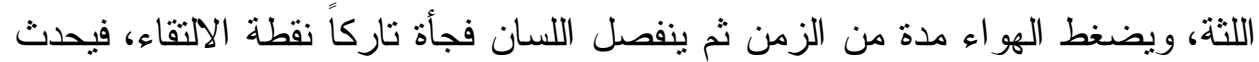

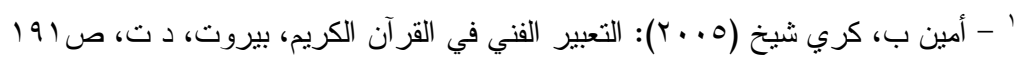

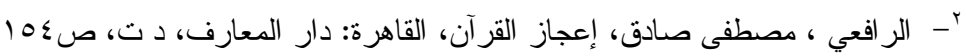




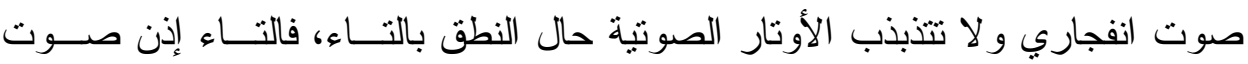

أسناني لثوي وقفة انفجارية مهموسة. (') إن حضور صوت التاء في هذه الآيات بصفته ومخرجه يشير إلى معنى الانفجار

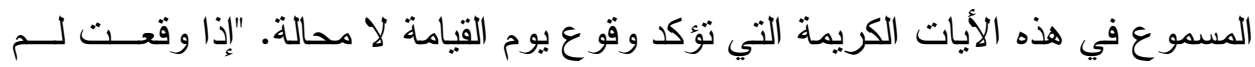

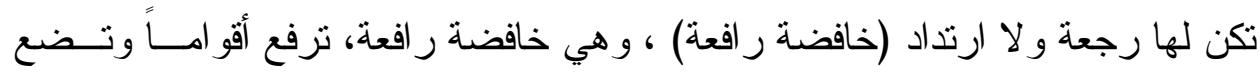

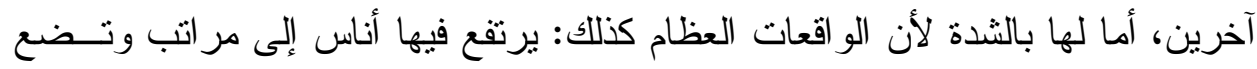

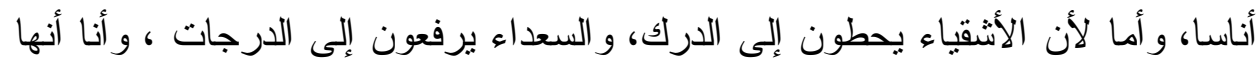

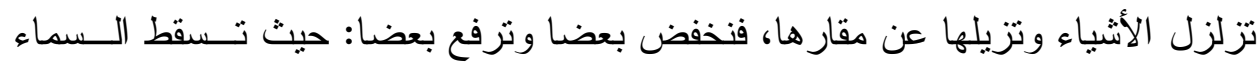

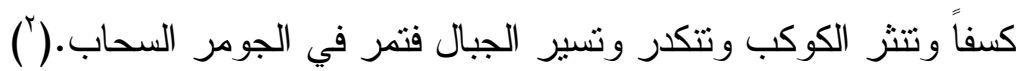

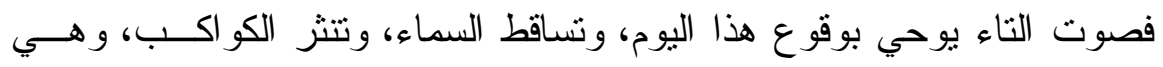

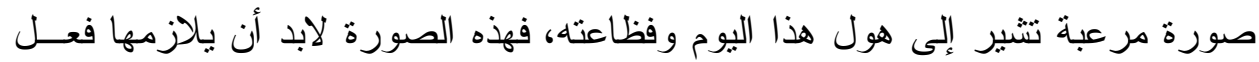

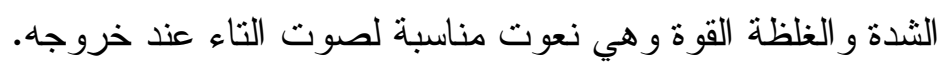

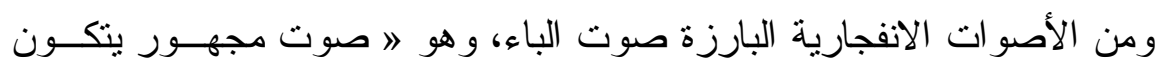

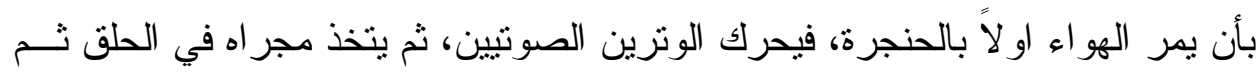

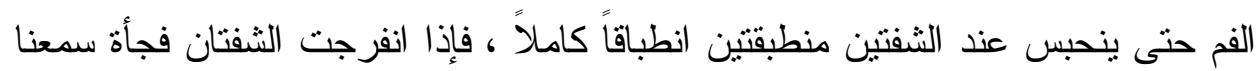

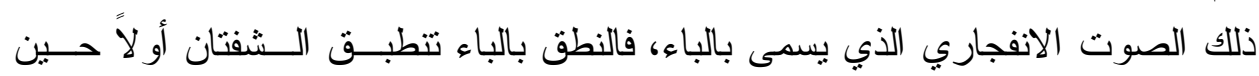

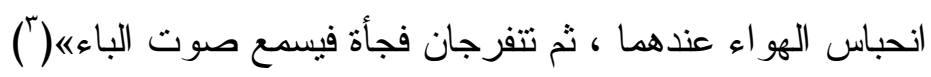
وقد يهمس صوت الباء العربي في بعض مواقعه كالباء نحو كتاب (بسكون

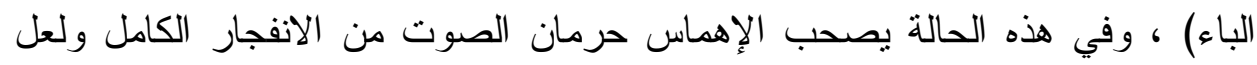
هذه من أحد الأسباب التي من أجلها نص العرب على وجوب تحريك الباء بصويت أي الاهي قلقلته، إذا كانت ساكنة ، حتى يتحقق النفجار و الجهر التام، وكذلك تدغم الباء الساكنة

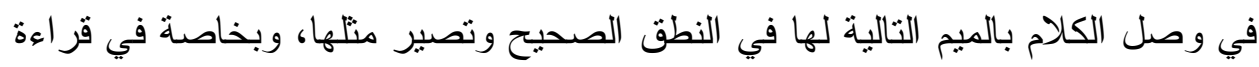

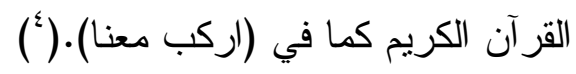

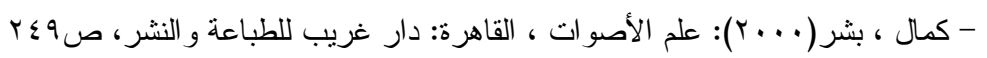

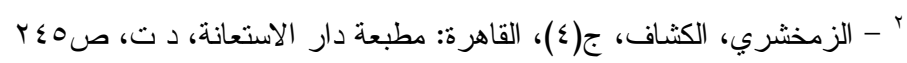

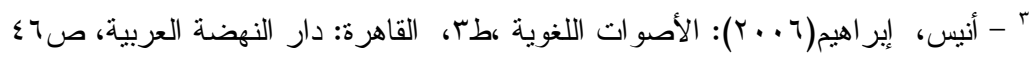

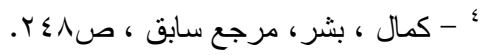




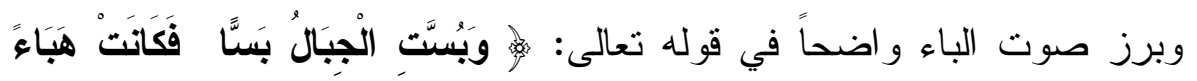

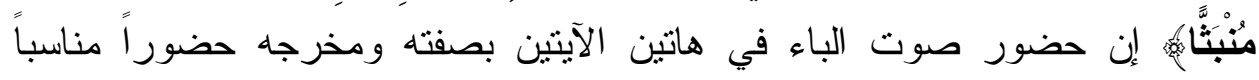
لسياق الكلام، إذ دل على عظمة الخالق في تفتت هذه الجبال ونسفها ، وجعلها كالهباء

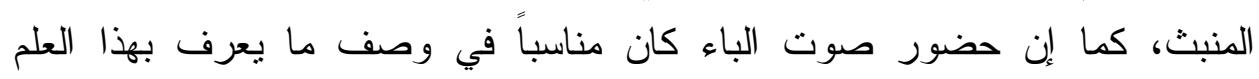

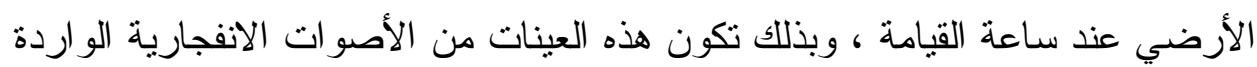

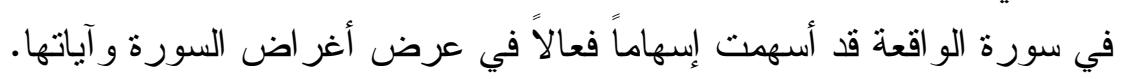

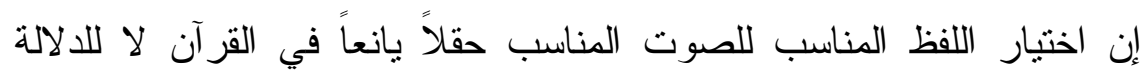

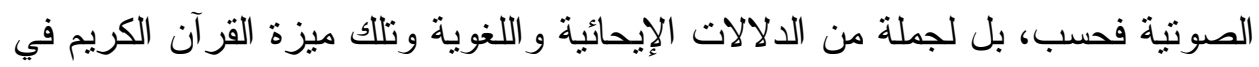

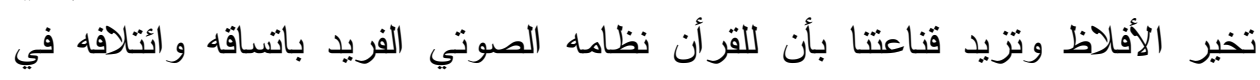
حركاتها وسكناته ومداته و غناته و اتصالاته وسكتاته اتساقاً عجيباً و ائتلافه ائتلافاً ر ائعاً

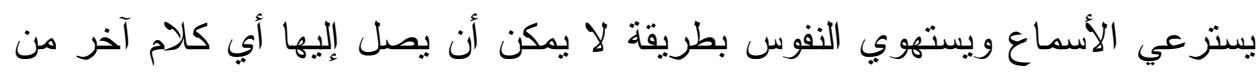

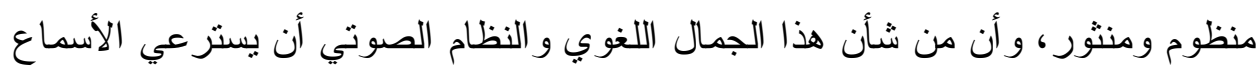

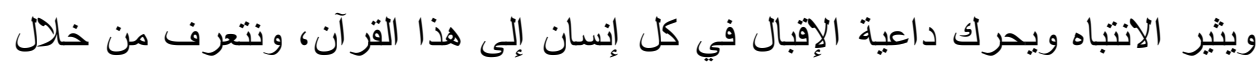
آيات سورة الو اقعة على ما بها من رو ائع ومويسقى لفظية. 


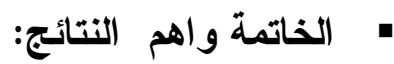

توصلت الاراسة إلى بعض النتائج، منها ما يلي:

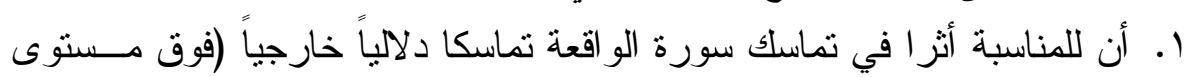

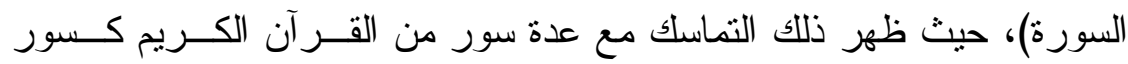
القيامة، وما قبلها (سورة الرحمن) وما بعدها (سورة الحديد).

r. الأسلوب القر آني أسلوب رفيع في شكله ومضمونه، فلا مجال لمقارنته بكــام

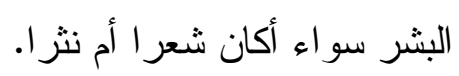

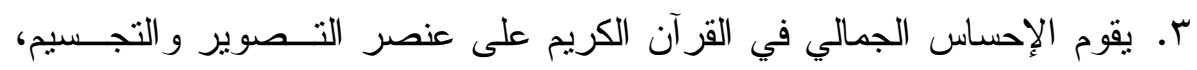
حيث يجعل القارئ كأنه يرى المشاهد و الوقائع رأي العين.

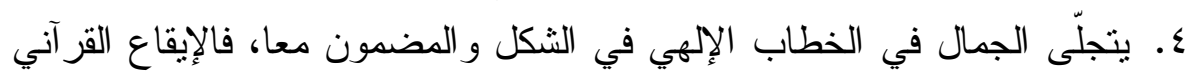

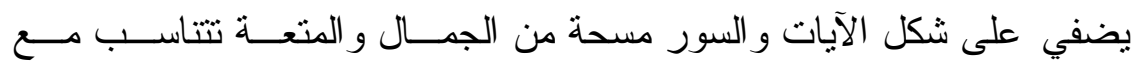
المعاني الربانية المعجزة. ه. تتضمن سورة الو اقعة العديد من الموسيقى اللفظية.

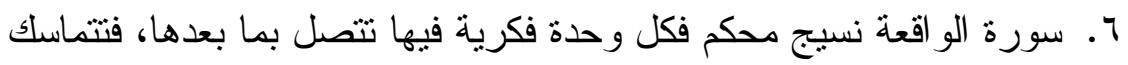

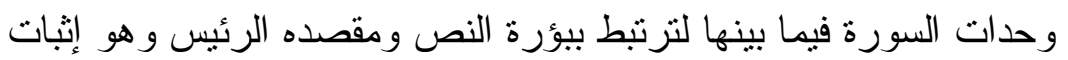

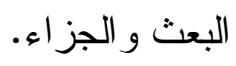

التوصيات:

في ضوء ما توصلت إلبه الدر اسة من نتائج يوصي الباحث بما يلي: 1- صرف المزيد من الهمم إلى الدراسات القرآنية في شتى الميادين. r- العناية بالبلاغة القر آنية في در اسات متتو عة بحيث تبرزها في أبهى صورة. 


\section{المراجع}

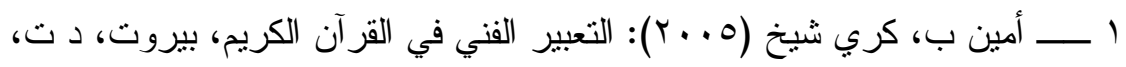

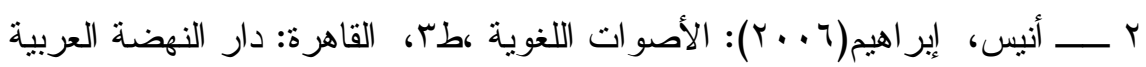

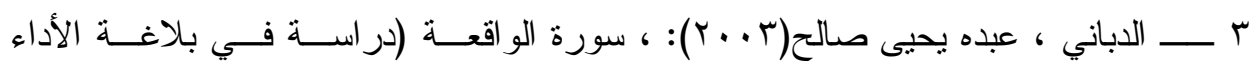

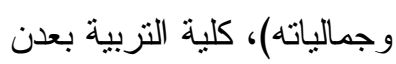

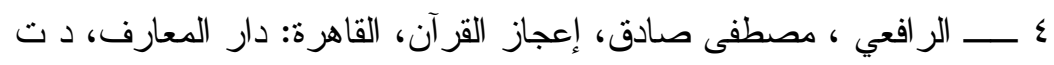

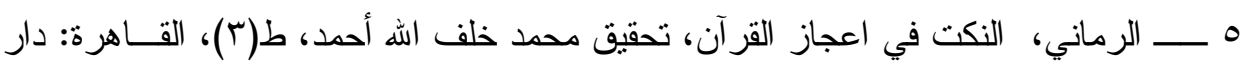
المعارف،

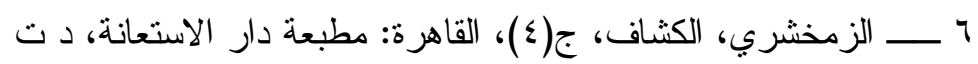

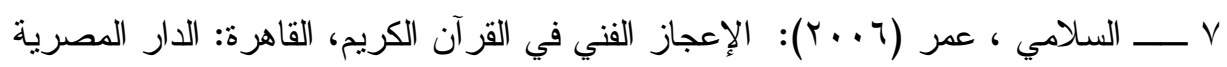

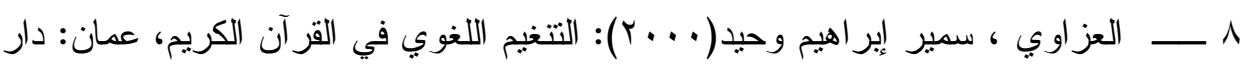
الضياء

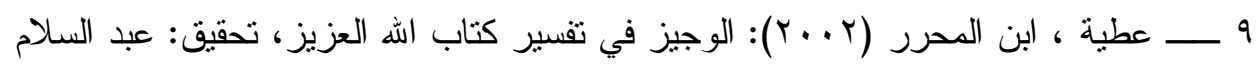
عبد الثافي محمد، بيروت: دار الكتب العلمية.

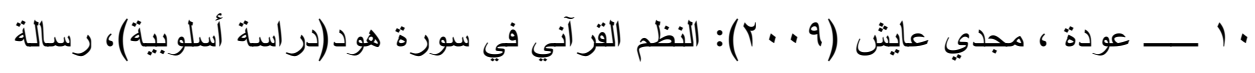
ماجستير ، الجامعة الإسلامية بغزة: كلية الآداب.

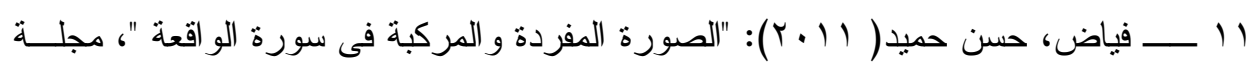

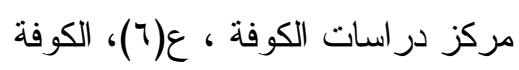

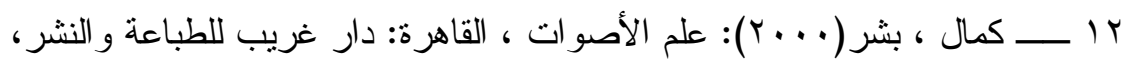

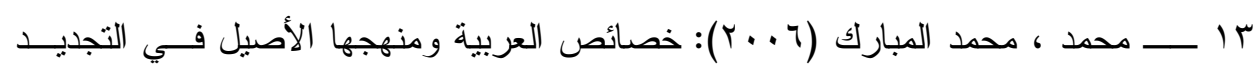

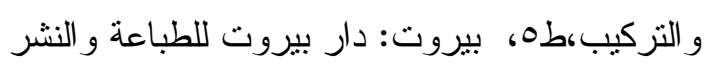

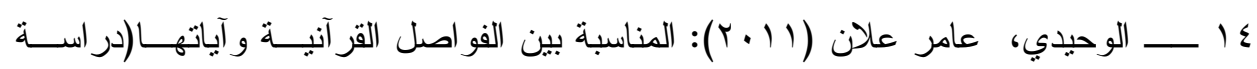

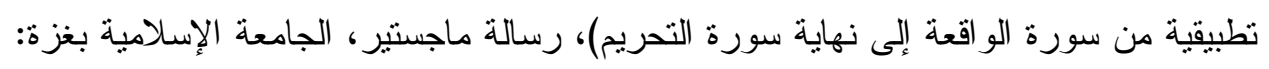
كلية أصول الدين 